\title{
Saúde e doença em Gestalt-Terapia: aspectos filosóficos*
}

\begin{abstract}
Adriano Holanda**
O trabalho se propõe a analisar a questão da Psicopatologia sob o prisma da Dialética, a partir das reflexões de Heráclito de Éfeso, e da Filosofia Dialógica de Martin Buber, como fundamentos para uma compreensão gestáltica da realidade. A idéia básica para se traçar uma elaboração da psicopatologia em Gestalt-Terapia é a noção de que "tudo é um todo", como contraponto a uma visão nosográfica tradicional, que considera a patologia como intrapsíquica ou individual. A psicopatologia é vista como produto da subjetividade que se caracteriza por ser, antes de tudo, inter-subjetividade. Partindo de uma epistemologia da Gestalt-Terapia, traça um panorama histórico dos pensamentos que formaram a Gestalt-Terapia, designando suas principais filosofias de base. Aproveita para tecer uma crítica ao modelo psiquiátrico tradicional com base nas idéias de Thomas Szasz. O cerne do trabalho é a consideração dialética da Gestalt-Terapia, a partir de três asserções: 1) Tudo é uma totalidade; 2) Tudo muda e 3) Tudo se relaciona com algo mais; e de suas correlações com o pensamento de Heráclito de Éfeso. O trabalho elabora ainda uma consideração da psicopatologia sob o prisma relacional, conforme Buber, que assinala para a patologia como um produto da desconfirmação do ser enquanto um existente. A psicopatologia surge, na realidade, como um evento relacionado ao diálogo ou, melhor dizendo, à falta deste. Com isto, mais uma vez concluimos que o homem deve ser entendido como um ser-de-relações. Utilizando uma linguagem buberiana, o fundamento da relação está na confirmação da existência do Outro e a psicopatologia é, pois, produto da desconfirmação. A conclusão final reconhece a Gestalt-Terapia como o resgate de uma ética do vivido.

Palavras-chave: Psicopatologia, Gestalt-Terapia, dialética, diálogo.
\end{abstract}

\begin{abstract}
Health and Illness in Gestalt-therapy: philosophical aspects

This paper proposes an analysis of the question of psychopathology and the view of Dialetics in the reflections of Heraclitus of Ephesus and the dialogical philosophy of Martin Buber, as foundations for a gestaltic compreension of reality. The basic idea to trace an elaboration of psychopathology in Gestalt-Therapy is the notion that "everything is a whole", like a counterpoint of a traditional nosographic view that considers pathology as individual or intra-psychic. Psychopathology is interpreted like a product of subjectivity that is caracterized, basically, to be an intersubjectivity. Beginning by an epistemology of Gestalt-Therapy, the article traces a historical panorama of the thinkings that formed Gestalt-Therapy, establishing its basics philosophies. The text improves a critics of the traditional psychiatric model based on Thomas Szasz ideas. The core of the paper is the dialetical consideration of Gestalt-Therapy, by three points: 1) Everything is a whole; 2) Everything changes and 3) Everything is related to everything else; and its correlations with the thinking of Heraclitus of Ephesus. There is an elaboration of psychopathology by the relational view, according Buber, who considers pathology a product of disconfirmation of the being whereas an existent. Psychopathology appears like an event related to the absence of the dialogue. We concludes that the human being might be understood like a being-in-relations. Using a buberian language, the foundation of the relation is the confirmation of the existence of the Other. The final conclusion recognizes Gestalt-Therapy as a theory preoccupied with the ransom of the ethics of living.
\end{abstract}

Key words: Psychopathology, Gestalt-Therapy, dialetics, dialogue.

\footnotetext{
* Revisão de trabalho apresentado no VI Encontro Nacional de Gestalt-Terapia/II Encontro Nacional da Abordagem Gestáltica, Florianópolis, 2 a 5 de Outubro de 1997.

** Psicólogo, Psicoterapeuta com Formação de Facilitador na Abordagem Centrada na Pessoa e Gestalt-Terapia de Grupos; Mestre em Psicologia Clínica pela Universidade de Brasilia; Doutorando em Psicologia pela Pontifícia Universidade Católica de Campinas; Vice-Presidente do Instituto de Gestalt-Terapia de Brasília.
} 
Este texto é produto de uma série de reflexões acerca do tema da psicopatologia a partir de um ponto de vista da Gestalt-Terapia, expressos em palestras e discussões com profissionais da área. O que me proponho a fazer é realizar um percurso epistemológico da GestaltTerapia, procurando encontrar nesta perspectiva da formação de seu pensamento, uma consideração do fenômeno psicopatológico.

A Gestalt-Terapia apresenta em seu corpo teórico-prático, um grande número de formulações basais, tais como o contato, o diálogo, a totalidade, dentre outros, alguns dos quais iremos nos referir aqui. Todavia, parto de uma consideração central. Creio que as palavras chaves da Gestalt-Terapia podem ser resumidas em duas, intimamente relacionadas: Dialética e Diálogo. Falar do binômio Saúde/Doença é tocar a realidade por inteiro, é retomar a questão do Normal e do Patológico, tantas vezes discutida e tantas outras indefinida.

\section{A Idéia da psicopatologia e crítica humanista}

Freud definia o homem saudável como aquele que "ama e trabalha". Talvez ele não tenha se dado conta da complexidade de sua colocação, o que o deixou aquém da compreensão da totalidade e do sentido da realização humana. Um exemplo disto encontramos na seguinte afirmação:

"Krafft-Ebing," especialista em perversões sexuais e amigo de Freud em Viena, disse que fome $e$ amor governam o mundo. Mas os dois esqueceram a fome e se concentraram nos tormentos do amor, o que foi pena, porque sexo, comida e bebida sempre andaram juntos na busca do prazer. Se a sexologia não se tornasse matéria científica distinta, se a busca de conhecimento fosse organizada de outra maneira, se tivessem surgido professores de felicidade para estudar a paixão pelo prazer como um todo, em todas as suas formas, uma visão diferente teria sem dúvida emergido. Impulsos físicos não são déspotas e não raro vêm a ser desobedecidos; gostos não permanecem fixos para sempre. A maneira de buscar-se outra vez o desejo está em considerar o que as pessoas querem à mesa e na cama como parte de um conjunto". 2

A realidade é muito mais do que uma simples forma de conceptualizar o homem. O ser humano não se resume aos seus instintos; estes fazem parte de um todo maior, de um conjunto envolvente. No decorrer da evolução das idéias, o conceito de normalidade foi sendo continuamente destituído de seu poder, a partir, principalmente, dos trabalhos de antropólogos culturais como Ruth Benedict, Margareth Mead, Bronislaw Malinowski, Gregory Bateson e outros, que assinalaram a fragilidade da noção de normalidade, visto esta ser variável em culturas, épocas ou situações. ${ }^{3}$

A Psicologia Humanista estabeleceu uma delimitação muito clara na consideração da psicopatologia ao abandonar a caracteriolo-

1.Barão Richard F.J.von Krafft-Ebing (1840-1902), nasceu em Mannheim, tendo estudado em Heidelberg e trabalhado no Hospital Burghölzli. Além de haver publicado um Manual de Psiquiatria, Krafft-Ebing ficou célebre por sua obra Psichopathia Sexualis, editado em 1886. Foi o primeiro a elaborar estudos sobre anomalias sexuais. E foi o responsável pela cunhagem dos termos sadismo e masoquismo (Morel, 1997).

2. Zeldin, 1996:88.

3. Ginger \& Ginger, 1995. 
gia nosográfica e partir para uma concepção mais abrangente. Afinal, a psicologia e a psicoterapia não são somente para "doentes", mas também para "doentes" ou, como dizia Perls com referência específica à Gestalt-Terapia, se tratava de "um método muito operante para ser reservado unicamente aos doentes".

A Gestalt-Terapia apresenta um discurso sobre a saúde e o funcionamento ótimo da personalidade ${ }^{4}$, com ênfase maior na saúde do que na patologia. Os trabalhos sobre psicopatologia em Gestalt-Terapia se devem, a princípio, aos esforços de Erving e Miriam Polster.

A potência da Gestalt-Terapia está no fato do terapeuta poder permitir-se ser impregnado de um contato intenso com o cliente, estabelecendo a dimensão relacional em psicoterapia $^{5}$.

Segundo Clarkson, a Gestalt-Terapia, em muitos países europeus, foi dificilmente aceita pela idéia de que não havia muita teoria. Isto gerou, em um determinado momento da evolução das idéias gestálticas, uma torrente de associações do tipo "Gestalt- e..." (Clarkson chama isto de "Gestalt and..." syndrome $)^{6}$

Creio que a idéia básica, central, de um pensamento psicopatológico em Gestalt-Terapia se refira à sua concepção de totalidade ou, parafraseando Clarkson, "tudo é um todo", ou seja, é virtualmente impossível apreendermos fenomenologicamente o Outro sem atentarmos para a sua totalidade. O grande erro da Psiquiatria tradicional, que impregnou e ainda impregna sobremaneira o pensamento psicopatológico atual, é desconsiderar a globalidade do indivíduo enquanto uma realidade interativa e interatuante, e pois, fundamentalmente dinâmica e dialética, para considerar a patologia como algo meramente individual e intrapsíquico, quando não intraorgânico. Sobre este aspecto relacional da subjetividade humana, temos que:

"E a terapia, na sua loucura, ao enfatizar a alma interior e ignorála do lado de fora, sustenta a decadência do mundo real", .

O que a Psicologia Humanista produz é uma inversão de valores. Enquanto a Psicanálise partia da "doença" para acessar a dimensão saudável do indivíduo, a Gestalt-Terapia, bem como toda a Psicologia humanista, se interessou desde cedo pelo desenvolvimento máximo do potencial humano, ou seja, parte de sua dimensão “saudável' para compreendê-lo como um todo. Como assinalam Ginger \& Ginger:

\begin{abstract}
"Após superar a clivagem sujeito/objeto da ciência tradicional e a clivagem normal/patológico do modelo médico, a psicologia humanista renunciaria também à clivagem cartesiana causa/consequência, para adotar um ponto de vista sistêmico, em que todos os fenômenos são considerados em interdependência circular: o homem é um sistema global aberto que inclui subsistemas..." 8
\end{abstract}

Esta concepção está em consonância com a evolução das idéias sobre a mente do ser humano. Se observarmos a história do pensamento ocidental, veremos que a nossa herança intelectual está toda ela calcada numa concepção dualista, determinista, contraditória, basea-

\footnotetext{
4. Delisle, 1992.

5. Delisle, 1992.

6. Clarkson, 1993.

7. Hillman \& Ventura, 1995:16.

8. Ginger \& Ginger, 1995:99.
} 
da numa perspectiva fortemente influenciada pela metafísica, em detrimento da dialética e sua intenção de globalização. Convém esclarecer esta questão.

Dialética significa, originalmente, a arte do diálogo. Independentemente da definição da genealogia da idéia (Aristóteles considerava Zenão de Eléa como o pai da dialética), considera-se a dialética como "o modo de pensarmos as contradições da realidade, o modo de compreendermos a realidade como essencialmente contraditória e em permanente transformação". 9

Neste sentido, o grande mestre da dialética da Antiguidade foi Heráclito de Éfeso (a quem iremos nos reportar mais adiante), para quem era inegável a qualidade de fluidez e movimento da realidade. Contrariamente a esta concepção, Parmênides ensinava que a essência do ser era a imutabilidade, a permanência.

"Essa linha de pensamento que podemos chamar de metafisica acabou prevalecendo sobre a dialética de Heráclito (...). De maneira geral, independentemente das intenções dos filósofos, a concepção metafísica prevaleceu, ao longo da história, porque correspondia, nas sociedades divididas em classes, aos interesses das classes dominantes, sempre preocupadas em organizar duradouramente o que já estava funcionando...". 10

A concepção metafísica de realidade tradição cultivada desde Parmênides, quando pronuncia sua máxima: “o ser é, o não-ser não é", é fundamental para o desenvolvimento das características tecnológicas e científicas de nos- sa cultura ocidental - impera, pois, em todas as concepções implícitas ou explícitas acerca da mente humana. Esta concepção se caracteriza por ser dualista e polarizada.

Este dualismo é explicitado no pensamento de Platão, através do seu "dualismo psicofísico" (corpo e alma), que poderíamos determinar como sendo o princípio do estabelecimento deste "dualismo metafísico" ao qual estamos nos referindo. Mas foi Descartes quem formalizou esta estrutura dualista quando:

"Através de seu Método dividiu a mente da matéria na célebre frase: 'Matéria é substância que tem extensão espacial mas não pensa; Mente é substância que pensa mas que não possui extensão material'. A mente cartesiana tem o mesmo papel aristotélico de princípio vital pois 'cogito ergo sum'", 11

Este dualismo metafísico é o gerador de todas as noções polares que encontramos no seio do pensamento ocidental, como por exemplo, as relações de causa-e-efeito - dualismo epistemológico - comuns à psicologia $\mathrm{e}$ às ciências naturais.

A tradição começa a cambiar quando do advento de disciplinas tais como a Cibernética ou a Engenharia Biomédica. No decorrer do anseio explicativo sobre as funções mentais, a dificuldade maior estava justamente em conseguir estabelecer uma rede de explicações lógicas para o repertório humano. Com a penetração da computação no meio social, a mente humana passa a ser considerada tal qual uma grande máquina, e os processos mentais, através de associações entre os estímulos do meio e

9. Konder, 1981:8.

10. Konder, 1981:9.

11. Carvalho, 1996:5. Encontramos sentença semelhante no pensamento de Parmênides, quando este afirma: “...pois $o$ mesmo é pensar e ser". 
as respostas consequentes do animal. Todavia, a hipótese mecanicista não consegue atingir a complexidade humana. Esta se revela igualmente dualista.

Nesta miríade de concepções dualistas da realidade, acaba que se generaliza o ideário fundamental, passando a considerar também o mundo sob este prisma dual. No que tange à estrutura conceptual saúde/doença, experimentase uma nova avaliação do real.

A Gestalt-Terapia procura, antes de tudo, retomar a questão do psicopatológico sob o prisma dialético, em contraposição às considerações tradicionais que são influenciadas pelo pensamento metafísico da Filosofia Ocidental; um pensamento dicotômico, dualista e que não abrange o todo. Esta avaliação dialética é antes de tudo fenomenológica, por se interessar pelo mundo privado, pelo mundo das vivências subjetivas.

\begin{abstract}
"A maioria das descrições psiquiátricas parece assumir de partida, que certos aspectos da vida das pessoas (por exemplo, amor e agressão) são centrais; e ao se concentrarem neles, a própria tese parece ficar provada. Para mim, a beleza da descrição fenomenológica é que ela procura revelar um mundo de experiêncas tal como ele é. O que ocupa o lugar central na descrição é aquilo que é central para a pessoa que vive a vida". 12
\end{abstract}

A idéia de uma psicopatologia fenomenológica pretende se alicerçar na tentativa de revelar o mundo ao Outro, no sentido de aquisição de novos significados. É curioso observar que toda a tradição ocidental de pensamento - que é dualista e segmentária - concorda com a perspectiva da sabedoria interna ou, como diria Rogers, a "sabedoria organísmica", ou como diria Van Dusen: "no centro da patologia está escondida a normalidade"13, conceito compartilhado pela Gestalt-Terapia, ou seja, apesar de valorizar sobremaneira um aspecto da realidade (basicamente o racional), corrobora com a idéia do vivido. Uma concepção dialética envolve os diversos aspectos - o racional, o emocional, o vivido imediato, etc - num conjunto complexo, do qual se busca a harmonização a partir da realidade imediata do sujeito vivente.

Se considerarmos o ser humano como um ser em ação ou um ser-no-mundo, na concepção heideggeriana, faz-se mister analisar as concepções clássicas de psicopatologia para elaborar uma crítica na direção tomada pela elaboração de Thomas Szasz, quando assinala para o "mito da doença mental".

As idéias de Thomas Szasz sobre a questão que cerca a doença mental, modificaram sobremaneira o quadro da psiquiatria geral. Antes de tudo, critica a própria denominação de "doenças mentais" como sendo enfermidades do sistema nervoso e, portanto, como doenças do cérebro e não da mente. ${ }^{14}$ Más condutas diferem de doença mental. A crítica de Szasz reside na questão do poder do psiquiatra, em tratar indiscriminadamente a pessoa humana a partir de rótulos. Isto nos faz lembrar de nosso querido personagem, o Dr.Simão Bacamarte, do famoso conto machadiano, O Alienista que, em nome da ciência e do saber, vai paulatinamente confinando em sua casa de tratamento toda a população da pacata Itaguaí. Dizia o digníssimo Dr. Bacamarte: 
"O principal nesta minha obra da Casa Verde é estudar profundamente a loucura, e os seus diversos graus, classificar-lhes os casos, descobrir enfim a causa do fenômeno e o remédio universal". ${ }^{15}$

Em continuidade às suas laboriosas pesquisas no terreno da loucura, conclui o Sr.Bacamarte que:

\footnotetext{
"A loucura, objeto dos meus estudos, era até agora uma ilha perdida no oceano da razão; começo a suspeitar que é um continente". 16
}

Eis que o continente domina o próprio cientista, que finda por sucumbir às suas próprias teorias.

A crítica fundamental de Szasz ao modelo tradicional de psicopatologia reside no fato de continuamente se procurar por causas intrínsecas ou extrínsecas - mas que sejam lógicas e racionais - ou seja, um claro comprometimento com a tradição filosófica dualista que separa a mente ou a razão do corpo e das sensações, desresponsabilizando assim o sujeito vivencial de sua própria vivência. Um claro absurdo. Neste sentido, parodiando Marx, coloca-nos Szasz que é a mente humana o "narcótico do povo". Segundo ele:

“...psiquiatria é a negação da realidade da vontade própria e da trágica natureza da vida; esta negação legitimada permite àqueles que procuram uma explicação neuromitológica para a maldade humana $e$ que rejeitam a inevitabilidade da res- ponsabilidade pessoal, tornar a vida um caso clínico e confiar sua administração aos profissionais de saúde (...).Os psiquiatras e seus poderosos aliados conseguiram, então, persuadir a comunidade científica, os tribunais, os meios de comunicação e o público em geral que as condições que eles chamam de 'distúrbios mentais' são doenças - isto é, fenômenos independentes da motivação ou vontade humanas". 17

$\mathrm{Na}$ discussão epistemológica do caráter subjetivo da essência humana, Szasz cita o filósofo da ciência Michael Polanyi, quando afirma que:

"O reconhecimento de certas impossibilidades básicas determinou as fundações de alguns dos maiores princípios da fisica e da química; $d a$ mesma maneira, o reconhecimento da impossibilidade de compreensão das coisas vivas, em termos de física e química, longe de determinar limites para nosso entendimento da vida, irá nos guiar para a direção certa". 18

Esta concepção é típica das abordagens humanistas de Psicologia, e contém forte componente socrático, quando o referido filósofo nos lembra que a sabedoria encontra-se em cada um de nós e que, pela maiêutica, pelo método dialogal, permite-se que este "conhecimento" interno, básico, surja, tal qual o fenômeno de Husserl. O conhecimento da ignorância (presente na máxima socrática: "tudo o que sei é que nada sei”) é a porta de entrada para o verdadeiro

15. Assis, 1996:14.

16. Assis, 1996:25.

17. Szasz, 1996:11.

18. Polanyi apud Szasz, 1996:11. 
conhecimento, pois permite a abertura dos canais perceptuais à realidade tal qual ela é, sem a prioris, sem concepções pré-concebidas; apenas com uma abordagem fenomenológica. Segundo Szasz:

“...não são classificações de distúrbios mentais que os 'pacientes têm', mas são relações de diagnósticos psiquiátricos oficialmente aceitos (...) O resultado é que poucas pessoas agora percebem que diagnóstico não é doença (...).Minha crítica à psiquiatria tem duas pontas, parcialmente conceitual, parcialmente moral e política. No âmago de minha crítica conceitual está a distinção entre o uso literal e metafórico da linguagem com a doença mental como metáfora. No âmago de minha crítica moral e política está a distinção entre referirse a pessoas crescidas como adultos responsáveis e como pessoas insanas irresponsáveis (quase crianças ou idiotas) - o primeiro tendo vontade própria, ao último faltando este atributo moral porque 'sofreria' de doença mental". 19

Faz mister, pois, considerarmos a realidade psíquica de uma forma mais global, mais dialética; e de tudo o que se concebe em termos de dialética e diálogo, dois pensadores surgem como absolutamente básicos: Heráclito e Martin Buber. Mas inicialmente convém relembrar o percurso de formação intelectual da Gestalt-Terapia.

\section{Os fundamentos epistemológicos da Gestalt-Terapia}

A Gestalt-Terapia se fundamenta numa miríade de influências e fundamentos filosóficos, o que a torna uma disciplina particularmente interessante, tendo em vista congregar no seu cerne, uma idéia central calcada na interrelação dinâmica de seus variados elementos.

Se fizermos um percurso histórico da determinação do pensamento da Gestalt-Terapia, veremos que a gênese, desenvolvimento e evolução desta se confunde com a própria caminhada de Perls. Podemos diferenciar as várias formas determinantes da Gestalt-Terapia em fundamentos filosóficos, teorias de base e antecedentes pessoais. ${ }^{20}$ Como fundamentos filosóficos, percebe-se claramente um direcionamento humanista na Gestalt-Terapia, com ênfase particular na Fenomenologia e no Existencialismo. Dentre as teorias de fundo, ou seja, as disciplinas basais, temos a GestaltTheorie ou Psicologia da Gestalt; a Teoria do Campo de Kurt Lewin e a Teoria Organísmica de Kurt Goldstein. Além disso, os antecedentes pessoais mais importantes são a Psicanálise (a destacar, além da figura de Freud, a forte influência sofrida por parte de Reich) e as Filosofias Orientais (em especial o Zen-Budismo e o Taoísmo).

Nesta miríade de influências, percebe-se claramente que a Gestalt-Terapia não poderia, como não pode ainda, ser considerada uma coisa simples. Uma outra influência foi muito significativa para Perls. Trata-se do seu interesse pelo teatro, o que o levou a travar contato com a excepcional figura de Stanislavisky, cujo

\section{Szasz, 1996:12-13.}

20. Ribeiro, 1985. Os antecedentes pessoais são, obviamente, referentes à figura de Fritz Perls. Todavia, como ele é, de fato e de direito, o mentor intelectual e principal articulador da Gestalt-Terapia e, como sua vida se confunde com a própria disciplina, faz sentido esta articulação. Uma excelente complementação a esta historicidade da Gestalt-Terapia pode ser encontrada em Ginger \& Ginger, 1995. 
principal legado foi a descoberta que "um ator pode viver um papel vivenciando-o verdadeiramente". 21

As bases, pois, epistemológicas da Gestalt-Terapia se assentam sobre uma significativa quantidade de influências e de informações, o que leva o gestalt-terapeuta a uma necessária e irremediável visão de totalidade, sendo absolutamente contrária a uma abordagem segmentada da realidade, sob pena de desconsiderar a própria realidade do todo.

Uma dessas bases mais importantes foi, seguramente, a Psicanálise. Acredito que, se tomarmos as abordagens humanistas em Psicologia (Gestalt-Terapia, Abordagem Centrada na Pessoa, Logoterapia, Psicologia Existencial, etc), poderemos dividi-las em abordagens fenomenológicas (ou com encaminhamentos mais voltados para a Fenomenologia clássica) e abordagens existenciais (ou direcionadas mais amplamente pelas correntes existencialistas) ${ }^{22}$. As abordagens mais comprometidas com o existencialismo são também aquelas mais relacionadas à Psicanálise, tendo em vista que o aproveitamento que a Psicanálise faz da Fenomenologia husserliana é muito mais limitado do que a relação estabelecida com as doutrinas existencialistas, tais como a de Heidegger, por exemplo. $^{23}$

Outra forma de reconhecer a influência psicanalítica da Gestalt-Terapia é encontrada na citação de Quattrini, quando afirma que:

"Eu diria que a psicoterapia da Gestalt é a outra cara da moeda, sendo a primeira a psicoterapia freudiana, a Psicanálise. Parecem estar muito distantes uma da outra, mas são simplesmente as duas caras da mesma moeda. Possuem um background filosófico distinto (...). $O$ ponto de vista filosófico de Perls éfenomenológico existencial; o de Freud é positivista (...). Em realidade, pondo a fenomenologia como base do conhecimento, ele [Perls] estava antecipando o que finalmente foi realizado dentro da teoria dos sistemas, onde a realidade começa a não ser as coisas nem as pessoas, e sim a relação, $a$ interação". 24

Este ponto de vista - que é o fundamental da Gestalt-Terapia - é o que podemos definir como um referencial organísmico, ou seja, valoriza-se, a partir do relacional, os aspectos emocionais do vivido do indivíduo. Isto significa dizer que o ser humano sente emoções, e estas não são mediadas simbolicamente, mas vividas no imediato, sentidas diretamente da nossa realidade.

Na Psicanálise, a mediação verbal e a instrumentalização através da interpretação, delimitam a suposição de que a realidade não pode ser tocada diretamente, mas tão somente por meio de signos e designações mitológicas produzidas pelo inconsciente. Na Gestalt-Terapia, em consonância com a tradição existencialista, desde Kierkegaard e Nietzsche, e passando por Husserl, Sartre, Heidegger, Merleau-Ponty,

\section{Quattrini, 1996.}

22. Uma expressão muito utilizada no meio psicológico é a denominação de determinadas abordagens como sendo "fenomenológico-existenciais". Convém assinalar que, embora considere que a Fenomenologia seja um agente genético do Existencialismo, as duas visões são distintas em muitos aspectos. Portanto, considero mais adequado utilizarmos expressões que guardem as particularidades de cada influência.

23. Em que pese o fato de Heidegger ser considerado um fenomenólogo e de desconsiderar a alcunha de existencialista, ele desenvolveu uma visão de realidade diferenciada da do antigo mestre em aspectos os mais diversos.

24 Quattrini, 1996:4-5. Grifos meus. 
Buber e outros, a realidade é a realidade do vivido, presente e imediato ou:

“...como dizia Merleau-Ponty, os fenômenos são a única realidade com que temos contato, mas também o que produz qualquer fenômeno dentro do corpo; qualquer percepção se produz dentro do corpo". 25

Assim, o significado, em Gestalt-Terapia (e em Psicologia Humanista em geral), não é o simbólico freudiano, mas o próprio vivido perceptual, o dado imediato da sensação humana. Substitui-se assim o "qual o significado" por "qual o sentido".

Este fundamento fenomenológico da Gestalt-Terapia é o que a torna tão completa. É através do método husserliano que se acessa o mundo interno do Outro em toda a sua complexidade, visto ser a tarefa da Fenomenologia ir às coisas mesmas ("zur Sache selbst"), ou seja, apreender o mundo tal qual ele se apresenta aos sentidos, e assim, analisá-lo. ${ }^{26}$

A superação do positivismo se dá pela apreensão da continuidade, ou seja, da idéia de que o processo cognitivo não é linear, mas circular, ou seja, a mente tem a capacidade de acumular uma infinidade de dados e posteriormente passa a relacioná-los, a conectá-los. Assim, através da redução fenomenológica, evidenciase o ser-no-mundo, o ser-em-situação, e delimita-se o caráter relacional de sua existência: o sujeito não é puro sujeito, nem o objeto é puro objeto; mas antes ambos se correlacionam, um em função do outro, um somente existindo em contato com o outro. Esta idéia já está presente no pensamento de Husserl, mas alcança sua radicalidade existencial na filosofia de Buber.
Neste aspecto, a redução fenomenológica se torna uma busca do significado intrínseco da vivência, uma procura do subjacente, e tem como consequência, a intuição das essências ("Wessensschau").

\section{“ $\grave{A}$ fenomenologia compete} apresentar de maneira viva, analisar em suas relações de parentesco, delimitar, distinguir da forma mais precisa possivel e designar com termos fixos os estados psíquicos que os pacientes realmente vivenciam. Visto que não se pode perceber diretamente um fenômeno psíquico de outrem, assim como se percebe um fenômeno físico, só se poderá tratar de representação, empatia e compreensão, a que poderemos chegar, segundo o caso, pelo meio de levantamento de uma série de caracteres e símbolos sensivelmente perceptiveis, por uma espécie de exposição sugestiva". 27

Esta colocação de Jaspers serve-nos de introdução à questão da aplicação da Fenomenologia à situação específica da psicoterapia. Uma análise fenomenológica nos posiciona, enquanto psicoterapeutas, diante da pessoa do cliente como um todo que vem até nós em busca de auxílio, de esclarecimento, e introduz a questão dialética da Gestalt-Terapia.

\section{A dialética da Gestalt-Terapia}

Petrûska Clarkson, em um excelente trabalho de exame da dimensão dialética da Gestalt-Terapia, assinala para três temas centrais na consideração da Gestalt: 
a) Tudo é uma totalidade;

b) Tudo muda; e

c) Tudo está relacionado a algo mais. ${ }^{28}$

Estes três temas colocam a Gestalt-Terapia numa posição muito confortável diante dos avanços atuais da ciência. Segundo a autora, seria a psicoterapia mais compatível e potencialmente direcionada para as descobertas emergentes, como a física quântica ou a teoria do caos, visto ter uma capacidade de flexibilidade e adaptação únicas, encontrada nas filosofias humanistas e dialéticas. Para compreendermos melhor esta questão, passemos à análise do que a autora chama de "trindade de totalidades".

\section{"Tudo é uma totalidade"}

Do primeiro tema - "Tudo é uma totalidade"-, extrai-se a idéia do holismo, ou a concepção que considera a totalidade, a globalidade como substantiva. A consideração do todo é uma das principais características da Dialética, quando concebe a realidade como uma intrincada rede de interações, onde tudo está interligado (uma concepção que atualmente possui muitos adeptos sob a roupagem da teoria sistêmica).

Encontramos a gênese deste tipo de consideração no pensamento de um dos mais importantes filósofos da Antiguidade: Heráclito de Éfeso, a quem Clarkson considera como "o original avô da Gestalt" ${ }^{\text {29 }}$. Heráclito, um pensador que viveu entre 536 e 470 a.C., é um dos filósofos mais importantes de toda a história do pensamento ocidental. Sobre ele Sócrates teria dito ter compreendido boa parte, embora fosse necessário um "mergulhador délio" para decifrar as partes não compreendidas. Nietzsche, por seu turno, assinalava que o mundo sempre teve e sempre terá necessidade de Heráclito.

Por Dialética entendemos o supremo método da discussão e, portanto, do diálogo. Mas também é dialética a consideração dos opostos num todo compatível e organizado. Esta organização se dá pela colocação da oposição no seio da realidade: não haveria progresso sem a oposição à estrutura vigente ou mesmo não saberíamos discernir o dia se não houvesse seu contraponto, a noite. Oposição, aqui, é entendida como a consideração dos opostos.

Neste sentido, a Dialética é o retrato fiel da realidade: constante oposição, movimento. E esta é a marca do pensamento de Heráclito de Éfeso, pensador que procurou mostrar uma realidade factual que se apresenta onde quer que esteja a natureza. ${ }^{30}$

O legado de Heráclito foi o reconhecimento da intrínseca unidade do fenômeno, ${ }^{31}$ sendo pois, um dos primeiros holistas da história. O conceito de "holismo" conforme utilizado aqui refere-se à "teoria que designa que o princípio fundamental do universo é a criação de conjuntos [wholes], isto é, sistemas completos e auto-contidos, do átomo à célula pela evolução das mais complexas formas de vida e mente: a teoria que diz que uma entidade complexa, sistema, etc., é mais do que a mera soma das partes". ${ }^{32}$ Esta concepção holística é uma das características mais centrais da Gestalt-Terapia, e está hoje disseminada na ciência em geral, a partir da teoria do Caos. Em termos gerais, isto é um resgate da concepção heraclítica de realidade.

Em Heráclito temos a consideração da unidade, a partir da presença do Logos em toda

\footnotetext{
28. No original: 1) Everything is a whole; 2) Everything changes; 3) Everything is related to everything else (Clarkson, 1993).

29. Clarkson, 1993:5.

30. Holanda, 1992.

31. Clarkson, 1993.

32. Schwartz et al., apud Clarkson, 1993:5.
} 
parte. O Logos heraclítico ${ }^{33}$ refere-se ao princípio ativo do Universo, ou seja, é aquilo segundo o qual as coisas acontecem, é o que governa a própria realidade, é a lei universal. O Logos assim, é para Jean Brun: "simultânea e paradoxalmente, um Sentido que nos é transcendente e uma significação que nos é imanente". 34 Imanência e transcendência fazem a composição do conjunto em Heráclito.

Comparemos agora esta posição com Perls, Hefferline \& Goodman ${ }^{35}$ quando assinalam que "cada estágio sucessivo é um novo todo", e este se caracteriza por operar como um conjunto independente, com "vida própria", como um todo concreto. Esta idéia está intimamente ligada à concepção de mudança contida no pensamento heraclítico.

\section{"Tudo muda"}

A asserção "tudo muda", conceito caro à Gestalt-Terapia, pois concebe a realidade como dinâmica e não como imutabilidade e permanência, é um dos pilares fundamentais de qualquer tentativa de estabelecer uma psicoterapia de base humanista.

$\mathrm{Na}$ história do pensamento, este dualismo mudança/permanência sempre foi tema dos filósofos, embora possamos estabelecer claramente duas correntes diferentes. De um lado, o pensamento gerador da Dialética, a concepção heraclítica de panta rhei; do outro lado, em consonância com a própria evolução cultural da ocidentalidade, temos a gênese do pensamento metafísico em Parmênides e a formalização da estrutura dualista em Platão, com sua dicotomia dos mundos.

Heráclito é o filósofo da mudança por excelência. O universo é um incessante conflito entre opostos, sendo que a única verdade indiscutível é que "tudo muda", em uma estrutura circular. É incrível a semelhança que encontramos entre o que Perls coloca sobre "não apresse o rio" e a máxima heraclítica: "não podemos descer duas vezes no mesmo rio, nem tocar duas vezes a mesma substância".

O que Heráclito observou, foi o caráter cíclico, contínuo das mudanças que ocorriam no mundo, ciclos constantes de transformação, permanentes, sejam em escala ascendente, sejam em escala descendente, mas quantitativa e qualitativamente equivalentes. Observa com isto que um momento sucede ao outro, necessariamente diferente do anterior, para logo em seguida suceder a outro momento.

Esta configuração cíclica, traz a noção de fluxo. Como consequência, não é mais satisfatória a noção tradicional de "homeostase":

"Contrariamente a algumas idéias da psicanálise, que enfatiza somente a homeostase, a Gestalt reconhece a necessidade do ser criar desequilibrio, para se esforçar em direção da evolução ou mudança criati$v a$, e reconhece a atividade desestruturante como uma parte neces-

33. A esta noção são dadas numerosas definições, algumas mesmo contraditórias. F.E.Peters (1974, Greek Philosophical Terms, New York University Press) aponta as seguintes definições: discurso, razão, definição, faculdade racional, proporção. Legrand, op.cit., p.57, questiona: "O que é então o Logos? Enumerou-se uma quinzena de traduções: Norma de mundo (Fränkel), Relação (ou "Proporção" pitagórica), Explicação “discursiva” (o que faz de Heráclito um pseudo-Eleata..!) ou até Razão (no sentido “racionalista', o que falseia gravemente o pensamento do efésio), Lei do Devir (Lassalle), Definição, Fórmula, Sentido da Fórmula, Enunciado, Narração, Lição, Coleção, Dizer (as exegeses de Heidegger parecem flutuar entre esses dois últimos sentidos), "negligenciando" o sentido de Narração, ou o sentido de Mito, e, definitivamente, a tradução cristã que assimila o Logos heraclítico ao do Evangelho segundo São João, via platonismo!".

34. Brun, 1988.

35. Citado por Clarkon, 1993. 
sária do ajustamento criativo ou transformação criativa". ${ }^{36}$

A idéia básica de Heráclito, de que o fluxo é constante, vem sendo corroborada pelas mais diversas pesquisas da ciência moderna, bastando lembrar o conceito de "estruturas dissipativas". O fluxo, em essência, é o "elemento primordial", é o Devir ou o vir-a-ser. Este vir-aser é antítese, luta, oposição entre contrários, revezar-se de vida e morte, não é puro devir linear; antes, se desenrola no interior de um círculo. Como no fragmento 76, "a vida do fogo nasce da morte da terra, a vida do ar nasce da morte do fogo, a vida da água nasce da morte do ar e a terra nasce da morte da água".

Para Heráclito, ao contrário dos pitagóricos, que afirmavam a unidade do mundo baseada na fusão, a unidade do mundo é luta, é dialética, apontando pois, para a tensão. Para ilustrar isto, Heráclito utilizava como analogia a imagem do deus Apolo, portador do arco e da lira.

\section{"Tudo está relacionado a algo mais"}

O terceiro tema é o tema do processo ou da dinâmica da interrelação. A questão ultrapassa o conceito de processo e atinge a idéia de contato em Gestalt-Terapia. Em outras abordagens encontramos noções semelhantes, como por exemplo, a idéia de "tele" do Psicodrama ou de "sincronicidade" em Jung. Isto traz à tona a noção de padrões de interconexão, significativa na existência humana ${ }^{37}$.

Não esqueçamos que isto inclui a noção de oposição e, portanto, de polaridades. O processo ao qual nos referimos traz de volta a concepção de relação, e com ela, a base da mudança em psicoterapia.
Inter-relação significa, a nível do ser humano, a própria dimensão da intersubjetividade e a superação da concepção linear e determinista que estabelece que as experiências infantis causam distúrbios na vida adulta.

Esta terceira asserção é, antes de tudo, a reafirmação do holismo. É a continuidade da consideração sistêmica da realidade. Como está presente em Heráclito, o fluxo, o ciclo, é ininterrupto e necessariamente interligado em seus elementos. E é nesta consideração da interrelação que encontramos o espaço do diálogo, e como, a partir dele, podemos entender a psicopatologia como um fenômeno existencial.

\section{Filosofia dialógica e psicopatologia}

O que é o ser saudável ou o ser "doente", do ponto de vista existencial ? Já assinalamos que o ser humano é um ser-no-mundo, segundo Heidegger e, portanto, sua existência está diretamente ligada a este mundo - seja de objetos ou de seres -, quando então o ser humano atribui significados à realidade.

É característico deste ser of fato de vivenciar, pré-reflexivamente, o fluxo do existir imediato. ${ }^{38}$ Este vivenciar é, antes de tudo, o vivenciar dos paradoxos, das oposições de nossa vida cotidiana. Neste fluxo ininterrupto de relações, as coisas vão também cambiando sentidos. Para se viver "sadiamente", deve-se ter "coragem de ser" como assinala Paul Tillich.

$$
\text { " } A \text { essência fundamental do }
$$
homem sadio caracteriza-se, precisamente, pelo seu poder dispor, livremente, do conjunto de possibilidades de relação que lhe foi dado manter com o que se lhe apresenta na abertu-

36. Clarkson, 1993:7.

37. Clarkson, 1993.

38. Forghieri, 1993.

39 Boss apud Forghieri, 1993:52-53. 
ra livre de seu mundo (...). O serdoente só pode ser compreendido a partir do modo de ser-sadio e da constituição fundamental do homem saudável, não perturbado, pois todo modo de ser-doente representa um aspecto privativo de determinado modo de ser-não",39

Esta é a essência da abordagem fenomenológica da psicopatologia: a compreensão do ser humano na sua totalidade e inextrincavelmente ligado à sua rede de relações. Assim, a palavra-chave é relação, e o nome primordial para esclarecer isto é o de Buber.

Buber, ao falar de reciprocidade no diálogo, diz que esta é uma qualidade que implica que as duas pessoas estejam envolvidas na relação. Na situação específica de um esquizofrênico, por exemplo, existe um obstáculo visível: a não-disposição do outro em sair de seu mundo próprio.

Isto nos reporta à questão da psicopatologia. Na Gestalt-Terapia, podemos considerar a psicopatologia como diretamente relacionada com uma relação inadequada com o Outro. Neste sentido, não falaremos de uma psicopatologia individual, mas de uma relação psicopatológi$c a$, ou de uma psicopatologia relacional. "Adoecer", em Gestalt-Terapia, é estar em desarmonia relacional, seja com o mundo em geral, seja consigo mesmo.

Nesta consideração dialógica da psicopatologia:

"Eu gostaria de reiterar o ponto de vista de que o dialógico é primariamente uma abordagem, uma atitude, uma orientação, uma perspectiva. Por último é uma radical mu- dança de paradigma. Quando tomamos esta mudança de paradigma seriamente, isso muda inteiramente o modo como abordamos a terapia.(...) Coloca o relacional no coração de nossa existência e em nosso trabalho como terapeutas. Reconceptualiza nosso entendimento do desenvolvimento humano e psicopatologia". 40

A rigor, a psicose ou qualquer outra psicopatologia estaria relacionada com o estreitamento da interação, com as limitadas vivências intersubjetivas. De fato, psicopatologia pode ser vista como uma significante fuga ou "solidificação" do entre a que se refere Buber. Hycner vai mais longe ao afirmar que a psicopatologia é resultado de um "precoce diálogo abortado". Isto significa que, no mais profundo modo de encontrar os outros, essa pessoa não é "ouvida" e sua voz torna-se monológica e tragicamente um "movimento interno". 41 Entenda-se por "solidificação do entre" a confluência total, ou seja, não sair do entre.

Quanto à questão do "diálogo abortado", lembro-me de uma definição dada por Rogers ao significado da palavra "esquizofrênico":

"Na medida em que tem algum sentido definido, significa que aqui está uma pessoa extremamente sensível à sua vivência interior e também às relações interpessoais com outros, que foi tão derrotada e traumatizada ao tentar utilizar sua sensibilidade; que se afastou tanto de sua vivência, como de um contato real com os outros. Além desta noção básica, a palavra esquizofrênico significa também para mim que todos aqueles cujo

40. Hycner, 1990:42.

41. Hycner, 1989. 
comportamento se desvia, e que não podem ser facilmente compreendidos, são atirados nesta cesta muito ampla". 42

A psicopatologia surge, na realidade, como relacionada ao diálogo ou, melhor dizendo, à falta deste. Com isto, mais uma vez concluímos que o homem deve ser entendido como um ser-de-relações. Utilizando uma linguagem buberiana, o fundamento da relação está na confirmação da existência do Outro e a psicopatologia é, pois, produto da desconfirmação.

Por "confirmação" Buber quer compreender a própria dimensão existencial do ser humano. Ocupando lugar central em sua fillosofia, temos que compreender inicialmente que o ser existe somente em relação.

\section{"O trabalho terapêutico acon-} tece na esfera do inter-humano, arealidade que liga um ser humano a outro ser humano. $O$ inter-humano transcende o grupo e o coletivo. Num grupo temos a realização do poder do coletivo, onde, em geral, o elemento mais importante, o pessoal, fica suprimido. Numa dimensão coletiva, a massificação dos sujeitos acaba por negar aspectos fundamentais e fundamentadores como a alteridade e a diferença, que atuam na própria determinação do sujeito $e$, posteriormente, da comunidade. A esfera do inter-humano envolve o face-a-face, o encontro do um-ao-outro, cujo desdobramento desemboca no dialógico. Não se trata apenas de uma relação de multiplicidade, mas de um evento muito maior". 43
O diálogo é, para Buber, o elemento central da existência. A própria subjetividade somente se realiża quando penetra no diálogo, quando é invocação do outro. Não há $E u$ em si. Para que ocorra o diálogo autêntico, é preciso se desenvolver uma relação que contenha algumas características:

a) Abertura de cada parceiro para ver o outro como ele de fato é; envolve uma compreensão fenomenológica que capacita a apreensão do todo, sem preconceitos;

b) Reciprocidade ou ação mútua de um sobre o outro, ação de um Eu sobre um Tu e desse Tu sobre o Eu;

c) Presença, pois o evento do encontro se dá no instante da reciprocidade, na imediatez, na intenção do presente, único tempo realmente vivencial, conforme já assinalara Santo Agostinho quando afirma que:

"Seria talvez mais justo dizer que os tempos são três, isto é, o presente dos fatos passados, o presente dos fatos presentes e o presente dos fatos futuros. E estes três tempos estão na mente e não os vejo em nenhum lugar. O presente do passado é a memória. O presente do presente é a visão. O presente do futuro é a espera". ${ }^{44}$

d) Responsabilidade, ou a autêntica resposta de um para o outro; o produto final de uma relação intersubjetiva.

No pensamento de Buber, os seres existem na mutualidade, na afetação mútua:

"Meu Tu atua sobre mim assim como eu atuo sobre ele. Nossos alu- 
nos nos formam, nossas obras nos edificam". 45

$\mathrm{Na}$ filosofia de Buber, a alternativa ao diálogo autêntico pode ser o monólogo ou o mero palavreado. Neste último não há encontro, não há mutualidade. Aí reside a diferença. Só há diálogo autêntico no falar-ao-outro, uma fala que se abre à descoberta do Outro.

"Na conversação genuína, os dialogantes se confirmam mutuamente como pessoas, o que não significa aprovação do que o outro faz, mas de perceber o outro como existente $e$ confirmá-lo como tal, o outro "se vê atuante como fonte de um dinamismo próprio", o que permite que haja diálogo entre adversários. Confirmarmos o outro é aceitá-lo como um ser em devir, é constituir o outro como parceiro de encontro, é acreditá-lo enquanto pessoa". 46

Em suma, confirmar o Outro significa acessar a plena totalidade do Outro. Considerar o Outro apenas em suas partes, desconsiderando o todo, o íntimo, o vivido, é "desconfirmá-lo". É considerá-lo por um prisma alheio à sua vivência, é considerá-lo pela ótica do externo ou mesmo da regra, seja do "normal" ou do "patológico", mas não é compreender o ser vivente. Assim, a patologia é produto de relações limitadas do ser com o mundo, e, como assinala Friedman:

"Se a confirmação é central na existência humana e interhumana, então se segue que a desconfirmação, especialmente nos primeiros estágios de vida, deve ser o fator mais importante na psicopatologia, ou o que é popularmente mal interpretada como 'doença mental". 47

A questão da desconfirmação pode ser encontrada em diversas teorias, como a de terapia familiar de Boszormenyi-Nagy, ou outras como Heinz Kohut, Harold Searles, Ronald Laing, Helm Stierlin e Carl Rogers.

Confirmar o Outro é tornar a considerálo como um ser responsável por sua própria vida, é considerá-lo como tendo poderes sobre suas relações, é afirmá-lo como existente. Esta é a mais profunda contribuição de Buber à psicoterapia. A reafirmação da responsabilidade.

\section{"Responsabilidade no sentido} de "prontidão", de "habilidade" a dar respostas. Responsabilidade como uma ação mútua, uma ação de um Eu para com um Tu, e desse Tu para com um Eu, em completa reciprocidade e alteridade". 48

O ser humano, como um ser histórico, é um ser total. O que a Gestalt-Terapia promove é um despertar do indivíduo à sua responsabilidade, como um exercício de escolha e de tomada de posse de sua própria vida. É a retomada da ética do vivido. O ser-existente é o que se abre à responsabilidade frente ao outro, é o que se coloca disponível ao contato, a presentificar e fundamentar a si próprio e ao Outro. Uma relação ética, antes de mais nada.

Se quisermos entender o fundamento da psicopatologia gestáltica, temos que considerar a dimensão humana em sua intersubjetividade, ou seja, toda relação humana é, essencialmente,

45. Buber, 1979:18.

46. Amatuzi, 1989.

47. Friedman, 1985:123.

48. Holanda, 1998b:121. 
inter-subjetiva. O Outro tem sua relação com a realidade a partir da relação com a minha experiência, num todo indissociável.

A proposta gestaltista para a psicopatologia reside numa mudança de enfoque: de uma consideração meramente descritiva dos quadros psicopatológicos, como o faz a psiquiatria tradicional, para uma visão que englobe a relação de complexidade que possuem estes fenômenos, onde o básico para a determinação de sua gênese, são os aspectos relacionais do vivido psicopatológico.

\section{Referências Bibliográficas}

Amatuzzi, M.M. (1989). O Resgate da Fala Autênti$c a$, Campinas: Papirus.

Assis, M.(1996). O Alienista, Rio de Janeiro: Ediouro.

Brun, J. (1988). Os Filósofos Pré-Socráticos, Lisboa: Edições 70.

Buber, M. (1979). Eu e Tu, São Paulo: Moraes.

Carvalho, L.A.V. (1996). As Teorias da Mente, Jornal do Brasil, Suplemento Idéias, 12/10/96, p.5.

Clarkson, P. (1993). 2,500 Years of Gestalt: From Heraclitus to the Big Bang, The British Gestalt Journal, 2, 4-9.

Delisle, G. (1991). A Gestalt Perspective of Personality Disorders, The British Gestalt Journal, 1, 42-50.

Delisle, G. (1992). I Disturbi della Personalità, Roma: Sovera.

Forghieri, Y.C. (1993). Psicologia Fenomenológica. Fundamentos, método e pesquisas, São Paulo: Pioneira.

Friedman, M. (1985). The Healing Dialogue in Psychotherapy, New York: Jason Aronson, Inc.

Ginger, S. \& Ginger, A. (1995). Gestalt. Uma Terapia do Contato, São Paulo: Summus Editorial.

Hillman, J. \& Ventura, M. (1995). Cem Anos de Psicoterapia...E o mundo está cada vez pior, São Paulo: Summus.
Holanda, A.F. (1992). Presença de Heráclito em Psicoterapia, Insight-Psicoterapia, Ano II, No.15, Janeiro.

Holanda, A.F. (1998a). Fenomenologia, Psicoterapia e Psicologia Humanista, Revista Estudos de Psicologia, Campinas, 14(2):33-4.

Holanda, A.F. (1998b). Diálogo e Psicoterapia: Correlações entre Rogers e Buber, São Paulo: Lemos Editorial.

Hycner, R. (1989). The I-Thou Relationship and Gestalt-Therapy, The Gestalt-Journal, 13(1):42-54.

Hycner, R. (1990). Between Person and Person, New York: The Gestalt Journal.

Konder, L. (1981). O Que é Dialética, São Paulo: Editora Brasiliense.

Leitão, V.M. (1987). O Enfoque Centrado na Pessoa no Tratamento de um Caso de Esquizofrenia, Psicologia, Teoria e Pesquisa, 3(3):262-281.

Morel, P. (1997). Dicionário Biográfico Psi, São Paulo: Jorge Zahar Editor.

Quattrini, P. (1996). A Gestalt-Terapia por Paolo Quattrini, Insight-Psicoterapia, Junho, 4-8.

Ribeiro, J.P. (1985). Gestalt-Terapia: Refazendo um Caminho, São Paulo: Summus.

Santo Agostinho (1984). Confissões, São Paulo: Edições Paulinas.

Szasz, T. (1996). Doença Mental ainda é um mito, Insight-Psicoterapia, Junho, pp.9-15.

Van Dusen, W. (1977). A Fenomenologia de uma Existência Esquizofrênica, In F.Perls \& Outros, Isto é Gestalt, São Paulo: Summus.

Zeldin, T. (1996). Uma História Íntima da Humanidade, Rio de Janeiro: Record. 